\title{
What do we know about managing aging teams? Lessons learned from the automotive shop floor
}

\author{
Christoph K. Streb, Franz Josef Gellert
}

\section{INTRODUCTION}

The issue of the demographic shift towards an older population in Western industrialized countries and the resulting aging labor pool available to organizations has been researched for many years now. Various disciplines thus address different issues regarding the aging individual, organization, or society as a whole.

In our field, however, we are mainly interested in analyzing how this particular demographic change affects the age composition of the workforce and, potentially, individual, team, and organizational interaction and performance. Moreover, managers and researchers alike do not merely analyze these potential challenges, but are impelled to find solutions to managing an aging workforce towards competitiveness.

Consider the automotive industry: as in many other sectors, value creation is largely the result of team work. Teams typically work in management and administration, in research and development, and in the projects of a specific functional area. Teams often work across functional boundaries and are the crux of an automotive company's organizational performance.

In automotive companies, one of the purest and most elementary forms of team work is found on the production lines, which realize the core business's value creation. Day by day, individuals convene, perform a specific task, or a whole set of tasks, and contribute to the realization of a product which, quite literally, is more than the sum of its parts. Together with all other organizational functions, it is this team work on the production lines that creates the business's core outcome.

However, since production is an important function of such an organization, the potential negative impact of age-related challenges on team performance and, thus, on organizational competitiveness is also evident. Our prior research on the aging workforce in this industry suggests that its aging workforce challenge lies in the physical and non-physical team work undertaken on production lines. The main issues are the time that aging team members require to recover from illnesses, reduced deployment flexibility due to physical constraints, and the loss of knowledge and skills due to the number of retirees (see Fig. 1). All these factors can affect the performance of a team and, thus, organizational competitiveness.

Top management often considers older workers costly, less flexible and adaptable to new technology, and less willing to cooperate and learn new skills. Conversely, research on physical labor, mental fitness, and on an aging workforce's competitiveness and overall performance has produced contradictory findings: while there is no evidence of a significant decline in overall cognitive performance, general physical deterioration cannot be disputed.

But what do we know about the performance of aging teams in organizational settings? Although there have been multiple studies on the older workforce's mental and physical abilities, we know little about an aging workforce's direct impact on team performance in labor-intensive work settings on the shop floor, and how teams can be successfully managed under such conditions. Consequently, we conducted an extensive, longitudinal study in two major automotive organizations, namely Daimler and Volvo, in order to examine the negative age-performance assumption. We argued that with an increasing average age, team performance on the shopfloor level will decline. Surprisingly, we found that the contrary is true: With a growing average age, team performance improved.

Our paper is presented in four main sections. We first provide a brief overview of how teams are organized in the Daimler and Volvo automotive sample. Second, we describe how the aging workforce challenge manifests itself on the team level in that specific work environment. Subsequently, 


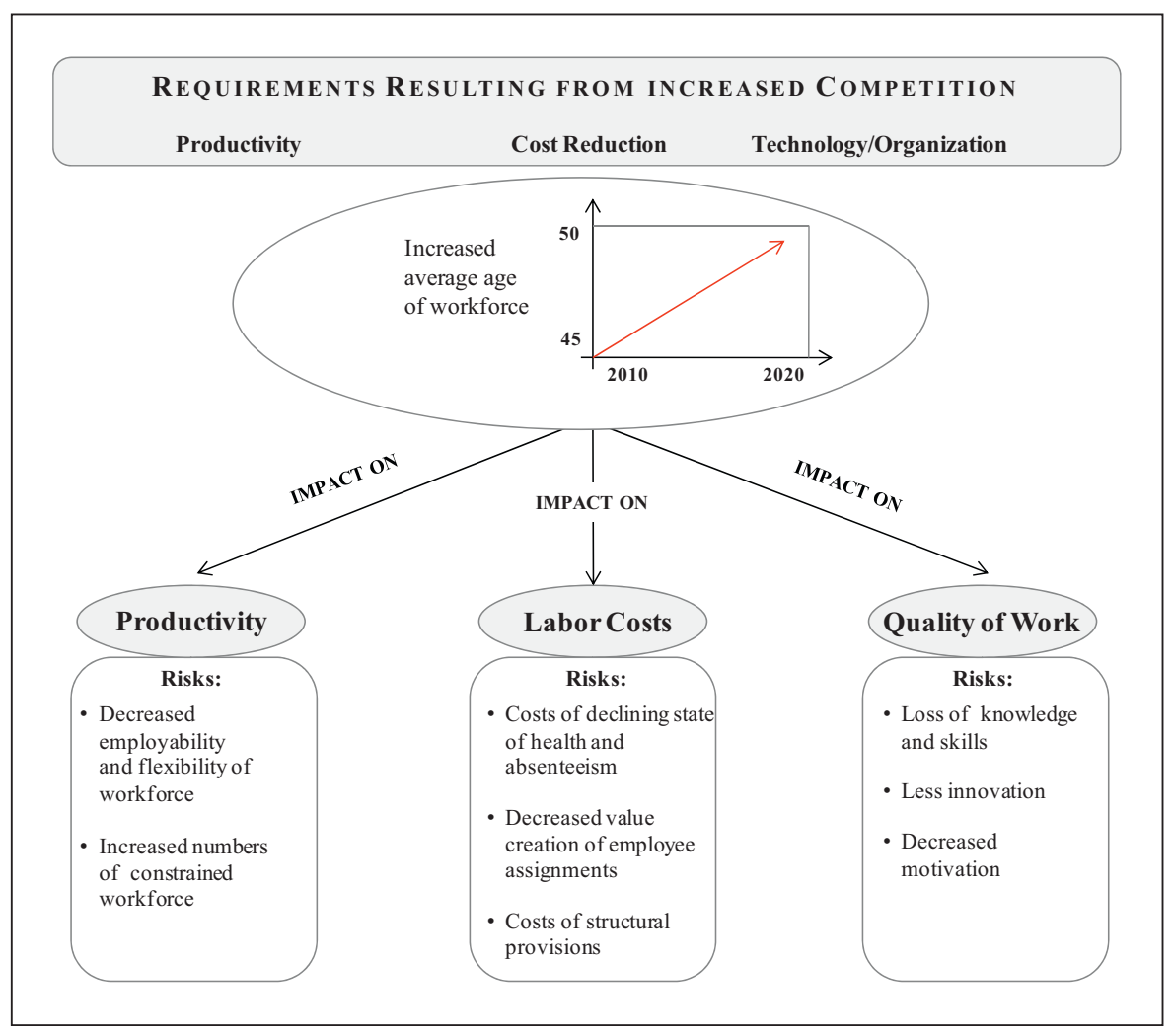

Figure 1 The aging workforce challenge in the automotive industry.

we illustrate the process that these organizations apply when faced with aging workforce challenges at the shop-floor level, before eventually deducing key lessons learned that could be applied in other organizations.

\section{TEAM MANAGEMENT ON THE AUTOMOTIVE SHOP FLOOR}

The Mercedes-Benz plant in Bremen, Germany - our study's first organizational sample - currently has around 13,000 employees, producing more than 260,000 cars per year. This makes it one of the largest plant facilities within the Daimler AG production network. As a pure production entity, threequarters of the employees are blue-collar production line workers. The departments are organized per product range, which includes the Mercedes C Class, CLK Class, GLK Class, SL and SLK Class, and soon also the new E Class models.

During the past few years, the plant's team work has been transformed from independent assembly teams to pure production-line-based teams organized in a so-called 'meisterei.' On average, a 'meisterei' consists of 36 employees divided into three teams of 12 people each. In many of these teams the average age is already approaching 50 years.

At the Volvo truck plant in Tuve, Sweden, about 150 bluecollar work teams, comprising more than 2000 individuals, annually produce 55,000 truck cabins in five production departments. The plant has recently changed to team work; this transition also entails a changing work organization, rotating team coordinators, and a development and incentive program to foster multi-functional behavior in all departments. The blue-collar production teams represent about 75 percent of all teams. A team has an average of 12 members. The workers' ages range from 20 to 63 , while age at entry is about 20 years. Approximately 60 percent of the workers are younger than 36 years, while 40 percent are older, which makes it age-wise a relatively younger plant than the Daimler one.

As illustrated in Fig. 2, the two organizational samples' production line team work is organized in a similar way: job rotation lies at the heart of the team work process. Production line rotation can be defined as an alternating system that schedules the deployment of employees in an organizational work setting within a defined range of workstations or tasks. By switching workstations and tasks several times per day, or even per hour, physical overexertion with all its shortterm and long-term health effects can be avoided, as can technical flaws due to repetitive and tedious tasks. The basic assumption is that rotation is beneficial with regard to variety, experience, the varying of physical strain, and job flexibility.

Beyond that, the departments are, as mentioned before, organized in groups and work teams. Each team leader supervises an average of 36 people in a group, split into three teams of about 12 people each. Within these teams, the norm is that each worker must be capable of performing all tasks assigned to the team, and must rotate to each workplace at least once a week. As a further norm, 30 percent of the team members must be capable of performing all the tasks assigned to the group. Another 10 percent of the team members must be capable of performing tasks that are assigned to groups other than their own. 


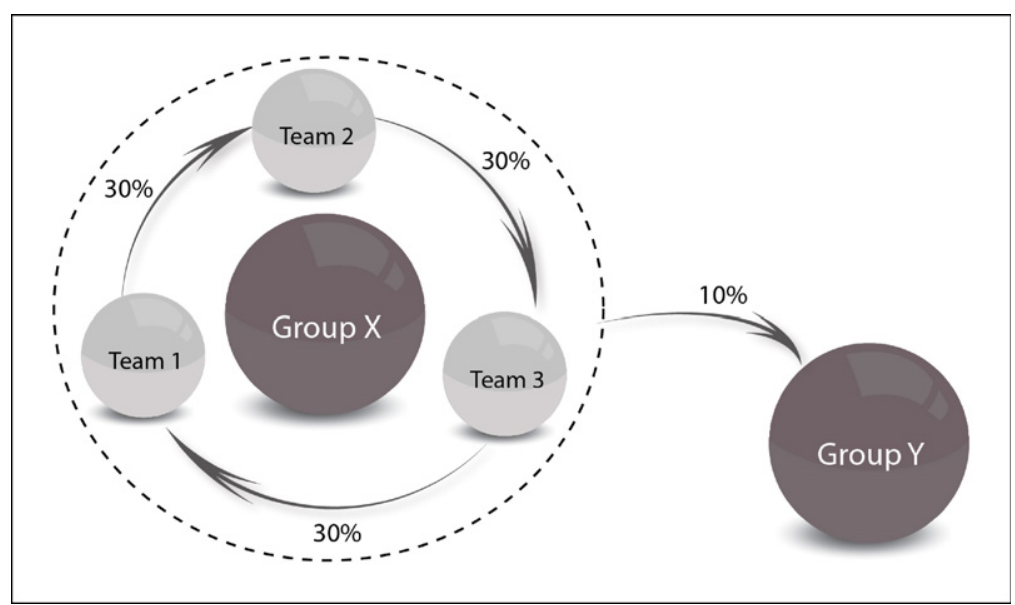

Figure 2 Exemplary team management on the automotive shop floor.

\section{WHAT CONSTITUTES THE AGING WORKFORCE CHALLENGE ON THE TEAM LEVEL?}

Car manufacturers are increasingly under pressure from international competition to reduce costs and improve quality. Consequently, the industry is currently setting more rigorous task performance standards, especially for workers on the production line. Jobs are analyzed in terms of their value creation and streamlined according to the core valuecreating tasks. Workers are then trained to perform according to a strictly laid out work design. This includes fixed workstations, within which assigned production line tasks have to be performed, fixed cycle times for each station, and single-step clocked jobs. The basic idea is to increase quality by making tasks and job training easier. However, the aging of the available workforce is thought to present a serious threat to this goal, as older workers seem to show decreased physical abilities.

Regardless of continuously improved ergonomic measures, mental and physical stress levels have also increased. Streamlining and standardizing production line work, aimed at improving the workforce's competitiveness, are factors which older workers might appreciate less and find less bearable, resulting in job burnout and, thus, a decrease in performance. However, team cooperation can have a significant positive influence on employee performance which, together with a team-member-oriented leadership style, could result in a higher job satisfaction level.

\section{Others' Perceptions of Older Workers}

Others' perception of older team members is obviously a critical issue when it comes to performance on the shop floor. On the one hand, management promotes an atmosphere of mutual understanding and collaboration; on the other hand, our interviews indicated that there are residual prejudices regarding older team members' work performance and, thus, their impact on the overall team performance.

Intergenerational cooperation is the most striking result to emerge from our research on the quality of the relationship between leaders and followers, as well as between employees. Once an effective team management process aimed at circumventing older employees' potential deficiencies and leveraging their specific experiences and skills has been implemented, the image of older employees changes to one of added value for the team. Subsequently, such a team reports a higher level of performance and job satisfaction, as well as a lower level of stress.

\section{Conflict between Generations}

In production teams on the assembly line, the increase in employees' number of days absent is related to the growing number of constrained workers. Moreover, we found an indication of a lack of employee involvement and commitment, which additionally affects their number of days absent. One of the possible explanations for this finding is that if the leaders and followers are of different generations, they seem to find it more difficult to interact effectively. If they are similar in age, or at least belong to the same generation, they are likely to favor each other and seem to create effective interactions more easily. Age-related self-categorization might therefore lead to similar attraction effects, but also leads to social competition due to age-related dissimilarity. Our argument is that a combination of additional factors, such as respect, cooperation, and autonomy, is an important aspect of the relationship level's quality.

\section{AN EXEMPLARY TEAM MANAGEMENT PROCESS IN AN AGING WORKFORCE ENVIRONMENT}

Given the described challenges that arise, how did the shop floor team leaders react to them? And how can this be translated into a more general aging workforce team management tool?

As described before, our study into the hypothesized ageperformance relationship indicated that, contrary to general expectations, team performance improved despite the increasing average age and despite the described challenges. While this is a very interesting and surprising finding in itself, the more relevant questions within the scope of this article are: Why can this be observed in this specific organizational context and, most important, what can other organizations learn from this? In the following section, we describe an 
exemplary aging team management process as generalized and summarized from our researched sample, before eventually deducing the key lessons learned in the concluding section.

\section{Analysis: Step One}

A team leader's first task is to undertake analysis. In contrast to the normally proposed aging workforce management tools, such as age-focused disquisition and, subsequently, adapted human resource and health management measures, analysis does not in this instance mean examining the supervised team's age structure and composition.

It is, of course, important that the team leader has an understanding of his or her workers' average age, as well as of their specific skill sets. In this case, however, analyzing aging-workforce-related issues on a team management level starts with the team leader's appraisal and clarification of whether individuals or various team members' observed or reported employment constraints are of a short-term or longterm nature. If the team leader observes potential issues that emerge from individual team members' increasing age, such as physical problems like backache, mental stress, or trouble coping with an adjusted work environment, he or she first has a personal conversation with this team member in order to explore the reasons for the observed problems and to find potential short-term solutions. This can, for example, mean that the job rotation plan is adjusted for a brief transition period to accommodate the specific individual's needs until he or she is fully employable again.

\section{Analysis: Step Two}

Only if the observed problems are chronic and cannot be individually solved on a short-term level, does the team leader resort to a widely known tool in the automotive industry: the group deployment profile. Depending on the organization, this can be a simple paper sheet table, an Excel chart, or sophisticated software in which the work content of each workspace covered by a team is detailed and objectively evaluated according to the physical and mental strain it imposes. Usually, it is the responsibility of the team leader, together with all the team members, to set up such a group deployment profile and to keep it updated if the workstation's tasks are changed.

In the next step of the analysis process, the team leader requires the assistance of the company medical officials or doctor. The doctor checks the specific constraints that team members are facing due to their increasing age and compares these with the specific job and workstation requirements outlined in the group deployment profile. If there is a discrepancy between the workstation requirements and the specific physical and mental performance possibilities and capabilities, the company doctor will identify this discrepancy, specify it, and discuss the result with the individual under scrutiny.

The result will be a detailed report of the specific performance deficiencies, but also a recommendation of how and where the person can be employed without limitations and in keeping with the group deployment profile. This includes temporary or quantitative constraints to performing certain jobs.
It is important to highlight that although this process requires the workers' personal details to be discussed openly with their superiors, this is by no means perceived negatively or as a threat. On the contrary, all parties involved are eager to cooperate, because a job deployment in line with the company doctor's recommendations usually results in an improvement in the overall workflow and job satisfaction.

\section{Redeployment and Relocation}

After the doctor's report, the team leader, the concerned team member, and a representative of the works council meet to discuss the results and decide on a new deployment scheme, including job rotation and work stations, aimed at employing the worker in a position that is as value creating as possible. In the best case, the employee can continue to work and rotate over workstations, so that even chronic physical and mental deployment limitations no longer have any effect on the performance and value creation. It is the team leader's responsibility to see that the worker then performs his or her new task to the full extent of the set job's requirements.

But what happens if the above measurements fail and the team member is still not employed at his or her full valuecreating potential? In such a case, the team leader has two possibilities: first, a decreased work performance output may be agreed upon for a shorter or longer term. This usually means that the worker's official working hours are reduced, and that he or she is limited to relatively easy tasks at a limited number of workstations that do not impose excessive strain. However, the resultant decreased value creation has to be balanced with the overall team performance, as well as an adjusted salary.

If even such a drastic measure fails and the worker cannot be employed in a value-creating capacity, it might be necessary to find deployment possibilities outside the original team. This could entail working with other workgroups or in departments with a more flexible job profile not limited by a production line's requirements. However, the team leader still needs to monitor the overall team performances across teams, groups, and departments to ensure that value creation is maintained or improved over time.

\section{CONCLUSION: TOWARDS AGING WORKFORCE TEAM MANAGEMENT}

The above-mentioned measures contributed considerably to the observed performance increase in our automotive sample. Fig. 3, for example, shows the measured improvements with regard to absenteeism and quality (number of deficient cars). After the successful implementation, absenteeism has on average declined from 8.2 to 6.9 percent, while quality has improved from an average of 7.9 percent deficient cars to an average of 5.8 percent. These numbers are considerable, but they become even more significant when considering the costs that are saved by such an improvement: On average, each team saves up to $\$ 2000$ per year, while the reduction of quality issues due to fewer repairs and retouching of products on the production line might account for saving of up to $\$ 350,000$ per year. 


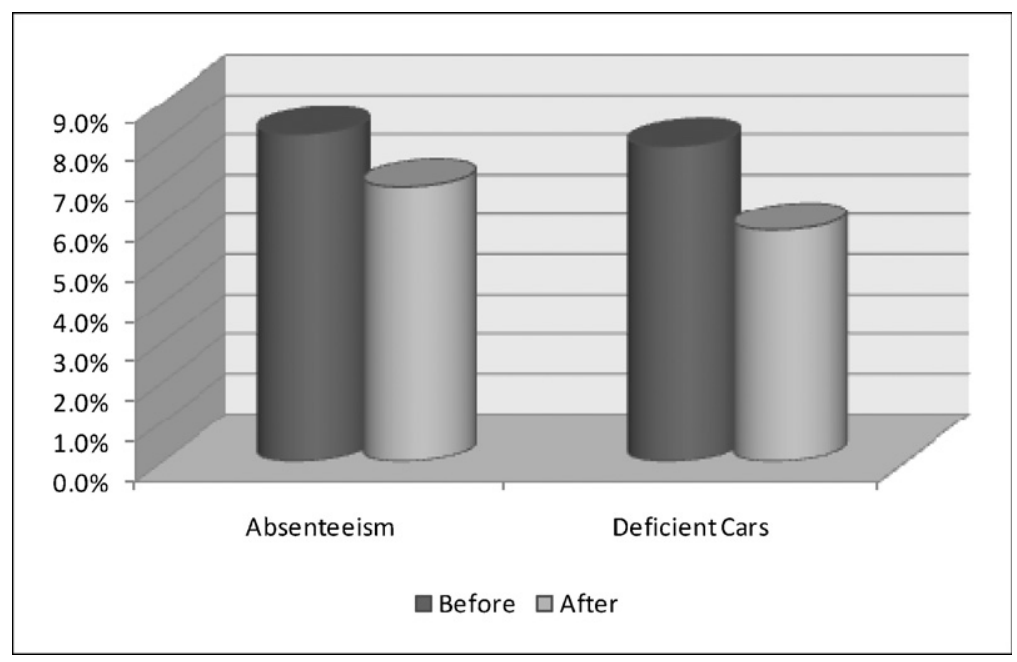

Figure 3 Average performance and productivity improvements.

While these are just average numbers per team, and considering that each organization consists of hundreds such teams, they clearly highlight the potential impact on the overall organization once the described approach has been implemented organization wide. A single production plant's total saving could easily accumulate to several million $\$$ per year.

However, one limitation is noteworthy: it is important to remember that the examples were drawn from automotive companies' physical work environment. Thus, they are only exemplary and need to be adapted before they can be applied to other organizations.

In this concluding section, we aim to refine and summarize our results into lessons learned that can be easily applied to other organizations, regardless of their industrial background. We also take the described challenges and the specific prejudices against older workers into consideration.

Thus, we propose the following steps that organizations facing similar challenges could consider and adapt for their specific requirements:

1. Appreciate age and experience: It is common knowledge that in an aging workforce environment, it is key not to discriminate against older coworkers, but to appreciate their specific tenure and experience. It is therefore not surprising that this is also a decisive prerequisite for a successful aging team management process.

As indicated in prior sections, there are still conflicts between age groups, with certain stereotypical views being held of older coworkers, although research on team performance draws a rather positive picture of age diverse teams, provided they are managed appropriately. This requires open communication and a management culture that appreciates and respects age and experience. The bad news is that there is no single, simple measure to achieve such an organizational culture, since it requires the management to devote time and to constantly communicate this objective. Nonetheless, without such an appreciation, the aging team management process will be significantly hampered. Team leaders faced with age diverse teams have to start with themselves first and constantly check and monitor themselves, as well as their teams, for stereotypical viewpoints.
2. Building trust: Issues regarding physical and mental deficiencies, whether age related or not, are generally perceived as extremely sensitive. Especially in a team environment, no one wants to be singled out and identified as responsible for reduced team performance, although it might be just temporary or due to serious (health) issues. Moreover, being treated as a constrained worker should not be associated with the fear of being laid off. While the team member has to trust the team leader that these issues will be treated as confidentially as possible and with the necessary care, in turn, the team leader needs to trust that the team member will address his or her physical or mental issues proactively as soon as they appear.

Again, there is no single tool with which to achieve such a level of mutual trust. It is the result of years of joint work and numerous leader-team interactions. However, it needs to be openly communicated that engaging in such an aging team management process is in the interest of both parties, in order to maintain and improve team performance and individual wellbeing, as well as job satisfaction.

3. Analyzing the requirements-performance gap: We found a group deployment profile tool, which allows team leaders on the shop floor to analyze the job and workstations' performance requirements, useful. Although we assume that not all production facilities in all industries are comparable, we strongly advise that existing workstations should be analyzed likewise. This should be done in close collaboration with the employees and workers, the works council, as well as the company medical officials or doctor, who can usually contribute the required knowledge of industrial medicine and ergonomics.

Equally strong networking and collaboration across hierarchies, functions, and departments need to occur when these requirements are matched with individual workers' analyzed performance capabilities. It is important to not only determine what they cannot do, but to specifically determine which workstations allow them to perform to their full potential and create value.

4. Redeploy and relocate: The last important measurement in the aging team management process is the redeployment, or even complete relocation, of individual workers 


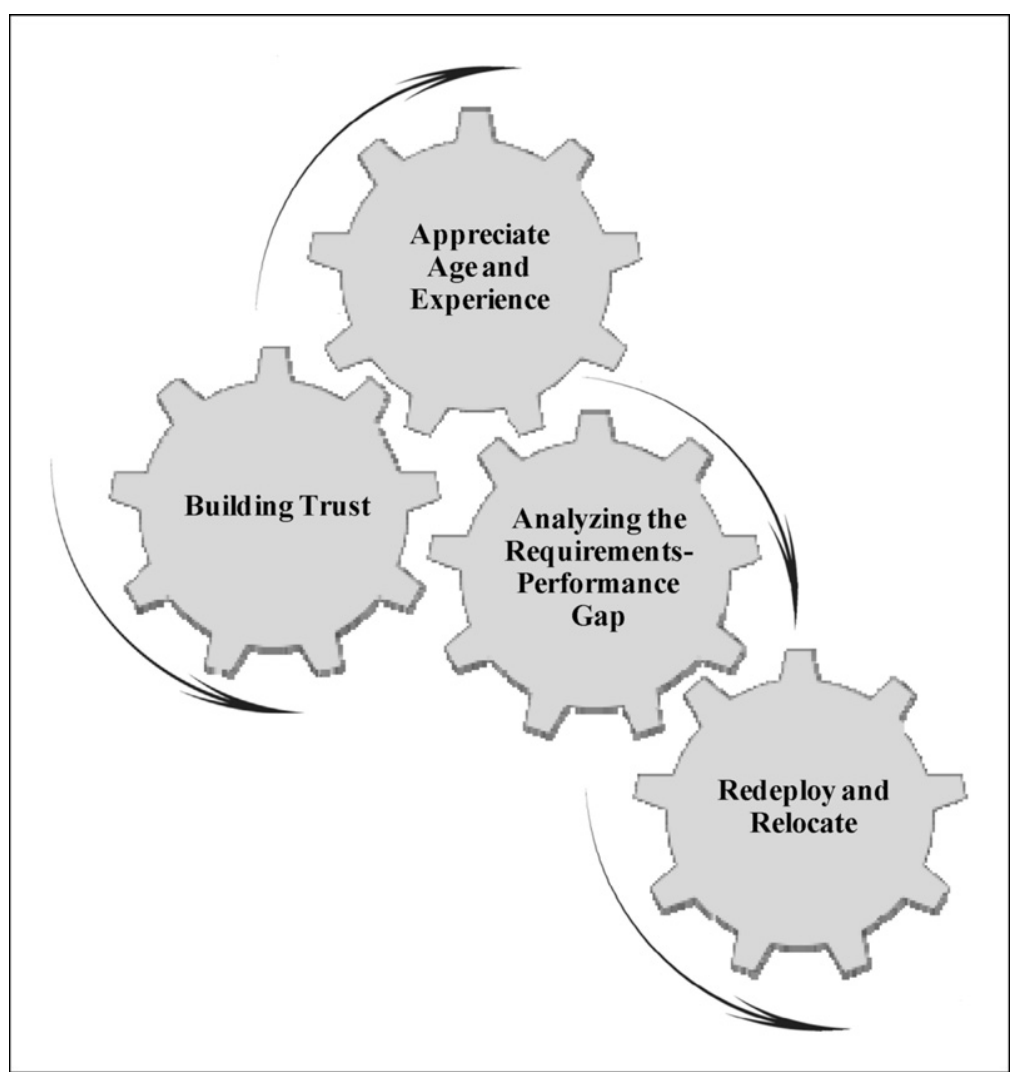

Figure 4 Cornerstones of a holistic aging team management process.

according to their specific performance and capabilities profile as matched with the job requirements. Again, the intention is not to single out low performers or to lay off people. The goal is to ensure that workers perform in accordance with their capabilities and the competitive goals of the organization as a whole. It may therefore be necessary to move some individuals to other areas and departments.

Consequently, it is important that a team leader is not limited by a single perspective, but will take both the overall organization and his or her entrusted team members' interests into consideration.

Fig. 4 illustrates the four cornerstones of a general aging team management process. It should be regarded as a holistic model that team leaders can use as a guideline for their activities. Nevertheless, these cornerstones should not be viewed as a binding step-by-step process. They merely summarize highly important issues in respect to an aging workforce in teams, especially when companies strive to improve their performance and organizational competitiveness. Therefore, these cornerstones need to be balanced. By creating the necessary appreciation of the topic and mutual trust between leaders and followers, by analyzing the potential requirements-performance gap, and by redeploying and relocating when and where these are necessary, team performance can eventually be monitored and become controllable. e-mail reprints@elsevier.com 


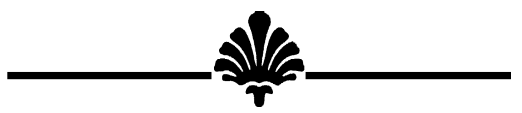

\section{SELECTED BIBLIOGRAPHY}

Our analysis of the age performance correlation, as well as the deduced recommendations for aging team management, is based on a mixed method study in two Daimler and Volvo manufacturing plants. Besides quantitative data and interviews, a number of internal, corporate documents and archival sources have been used; these are available upon request.

For more details on counterbalancing individual shortcomings by compensating for them - called the selective optimization concept - see, for example, P.B. Baltes, "On the Incomplete Architecture of Human Ontogeny: Selection, Optimization, and Compensation as Foundation," American Psychologist, 1997, 52, 366-380, or A.M. Freund and P.B. Baltes, "Life-management Strategies of Selection, Optimization and Compensation: Measurement by Self-report and Construct Validity," Journal of Personality and Social Psychology, 2002, 82, 642-662.

For research that explores the leader-follower relationships with respect to age as the dependent variable of team performance, refer to E. Kearney, "Age Differences between Leader and Followers as a Moderator of the Relationship between Transformational Leadership and Team Perfor- mance," Journal of Occupational and Organizational Psychology, 2008, 81, 803-811; and for aging team performance in general we recommend L.P. Pelled, "Demographic Diversity, Conflict, and Work Group Outcomes: An Intervening Process Theory," Organization Science, 7, 1996, 615-631, as well as S.J. Peterson and B.K. Spiker, "Establishing the Positive Contributory Value of Older Workers: A Positive Psychology Perspective," Organizational Dynamics, 2005, 34, 153-167.

For another work on general aging workforce management, especially with respect to Daimler, see C.K. Streb and S. Voelpel, "Analyzing the Effectiveness of Contemporary Aging Workforce Management: The Case of Daimler AG," Organizational Dynamics, 2009, 4, 305-311, or S. Voelpel and C.K. Streb, "A Balanced Scorecard for Managing the Aging Workforce," Organizational Dynamics, in press. With respect to specific preliminary research at Volvo, see B.S. Kuiper's book Team Development and Team Performance, Responsibilities, Responsiveness and Results: A Longitudinal Study of Teamwork at VOLVO Trucks (Umea: Labyrinth Publications, 2005).

Christoph K. Streb is an assistant professor and SOM Research Institute Fellow at the Department of Innovation Management and Strategy at the University of Groningen. His Ph.D. dissertation was based on his research on the constituting elements of aging workforce management in the automobile industry. His current research focuses on related issues, specifically the implications of the aging workforce for small business management and entrepreneurship. He is the author of several publications on the topic of aging workforce management and serves on the advisory board of distinguished companies, offering consultation on related matters (Faculty of Economics and Business, University of Groningen, Nettelbosje 2 (WSN 416), 9747 AE Groningen, The Netherlands. Email: c.k.streb@rug.nl).

Franz Josef Gellert is a senior lecturer and researcher at the Hanze University of Applied Sciences in Groningen, where he has taught since 2001. He has held various management positions in trade and industry. At Hanze University he specializes in marketing, economics and management. His research interests include social behavior, management, organizational behavior, and all work and age-related issues. He has published articles and books related to demographic changes, aging workforce, and work developments. Furthermore, he is interested in team development and team dynamics (Hanze University of Applied Sciences, International Business School, I Building-005, Zernikeplein 7, 9704 AA Groningen, The Netherlands. Tel.: +31 050595 2347; fax: +31 050595 2370; email: f.j.gellert@pl.hanze.nl). 